Article

\title{
Cooperation Intensity for Effective Policy Development and Implementation: A Case Study of Thailand's Alternative Energy Development Plan
}

\author{
Haruthai Chenboonthai ${ }^{1}$ and Tsunemi Watanabe ${ }^{2, *}$ \\ 1 Graduation School of Engineering, Kochi University of Technology, Kami 782-8502, Japan \\ 2 School of Economics and Management, Kochi University of Technology, Kochi 780-8515, Japan \\ * Correspondence: watanabe.tsunemi@kochi-tech.ac.jp
}

Received: 12 May 2019; Accepted: 24 June 2019; Published: 26 June 2019

\begin{abstract}
This research examined cooperation among core Thai government organizations involved in achieving the energy-from-waste (EFW) targets stipulated in the country's 2015 Alternative Energy Development Plan (AEDP). To this end, we used the institutional analysis and development (IAD) framework to illuminate the intricacies of such collaboration, which reflects interactions that flow logically from the decisions and measures taken by actors as they deliberate over relevant situations. Data were obtained mainly from government documents and in-depth interviews with employees of the collaborators that are directly involved in the development and implementation of AEDP 2015. The concept of cooperation intensity was used to inquire into the cooperative interactions of the aforementioned government organizations and analyze the factors and conditions that influence these actors' decision to work with one another. We focused on the effects of institutions on cooperation under the AEDP policy process. To strengthen the novelty of this work, we categorized cooperation intensity into five levels, which can serve as guidance in the evaluation and improvement of collaborative endeavors. These levels are reflected in collaboration through (1) the pursuit of common goals and mutual benefits, (2) the pooling of resources, (3) the sharing of responsibilities, (4) the synchronization of activities, and (5) the monitoring of partners. Using the proposed cooperation intensity levels, we identified the following causes of ineffective cooperation: Differences in perceptions of problems related to municipal solid waste (MSW) and the prioritization of solutions put forward by the individual actors; the actors' commitment to different solutions; the inconsistency among responsibilities, actions, and control over the expected outcomes of the actors; the failure of the actors to clarify and synchronize related and duplicate policy activities; and the unwillingness of the actors to undergo checking and monitoring. Overcoming these problems necessitates the enhancement of communication, which would reinforce cooperation given that effective communication leads to perfect information and an improved understanding of other actors.
\end{abstract}

Keywords: cooperation intensity; IAD framework; government organizations; energy-from-waste (EFW); rules-in-use; effective communication; AEDP 2015

\section{Introduction}

Similar to other developing countries [1], Thailand is now facing challenges that arise from the growth of economies, populations, and urbanizations-that is, increased energy demand, environmental degradation, global warming effects, and municipal solid waste (MSW) generation and management problems. MSW management, in particular, has caused the country critical problems that required urgent resolution, such as rising MSW generation, the limited capacity of landfill sites, and environmental effects on surrounding areas. Compounding these issues is insecurity in Thailand's 
energy sector given the country's substantial dependency on imported fossil fuels and petroleum in serving national energy consumption demand. To illustrate, $60 \%$ of the total energy consumption in 2017 was satisfied through imported fuels, of which around $80 \%$ is made up for crude oil [2]. Seeking alternative energy resources has thus been a crucial difficulty for the Thai government.

As reflected in global trends, one of the most potentially efficient approaches to satisfying energy demand and dealing with MSW management problems is the conversion of MSW into energy-from-waste (EFW) products [3], which can be considered as a kind of bioenergy resources [4]. EFW products can also be used as an environmentally friendly bioenergy resource for electricity, heat, and/or transport fuel generation [4]. Similar to biomass, EFW product is regarded as a renewable and carbon-neutral energy resource used to replace and/or reduce usage of fossil fuels and coal, which are considered as the important sources of $\mathrm{CO}_{2}$ and NOx emission [5-7]. Such products therefore play an important role in mitigating the emission of greenhouse gas (GHG) [6].

For this reason, the government has promoted and implemented the conversion of MSW into EFW or waste-to-energy (WTE) products as a practical strategy for resolving national MSW management problems, reducing the burden imposed on landfill sites, fulfilling energy demand, and reducing $\mathrm{CO}_{2}$ production and global warming impacts. This strategy is part of Thailand's 2015 Alternative Energy Development Plan (AEDP), which is the government's initiative for minimizing reliance on imported energy and cultivating domestic alternative energy resources, especially EFW. At the end of the plan's implementation in 2036, the proportion of renewable energy used in the country is forecast to increase to $30 \%$ final energy consumption, thereby replacing around 39,388 ktoe of fossil fuel utilization and reducing GHG emissions by around 140 million $\mathrm{tCO}_{2 \mathrm{eq}}$ [8]. Under the ultimate goals, $550 \mathrm{MW}$ of electricity and 495 ktoe of heat would be accounted for by the achievement of EFW targets [9].

The conversion of MSW into energy is gaining momentum as a preferred MSW management strategy in Thailand, and feed-in-tariffs (FiTs) for WTE-based electricity generation is supported by the government (Table 1) [10]. To date, however, the country has only 39 WTE plants with an electricity generation capacity of around $313 \mathrm{MW}$ and three WTE incinerators with a heat generation capacity of approximately 47 ktoe $[9,10]$. Achieving the EFW targets set forth in AEDP 2015 requires relevant organizations to cooperate with one another in establishing an appropriate and desirable FiT for heat generation from MSW. Through collaboration, these organizations can jointly support and encourage MSW-related development and investment.

Table 1. Feed-in-tariffs (FiTs) for electricity generation from municipal solid waste (MSW) in Thailand.

\begin{tabular}{ccc}
\hline Generation Capacity & FiT (Thai baht/unit) & Period of Supports (years) \\
\hline$\leq 1 \mathrm{MW}$ & 6.34 & 20 \\
$>1-3 \mathrm{MW}$ & 5.82 & 20 \\
$>3 \mathrm{MW}$ & 5.08 & 20 \\
\hline \multicolumn{3}{c}{}
\end{tabular}

Numerous efforts have been initiated to satisfy requirements for EFW development, especially the elimination of MSW management and EFW technology limitations, but such endeavors disregarded the importance of cooperation among relevant government organizations in sustainable and holistic EFW development and effective EFW policy formulation and implementation. In particular, energy policy creation and enactment in accordance with waste management directives is required given that government organizations involved in energy and waste management must cooperate to ensure the feasibility of EFW development and investment and to derive value from these projects. Unfortunately, such partnership has not arisen in the Thai context, with ineffective cooperation among governed institutions weakening and impeding EFW development in the country. Nevertheless, an optimistic outlook can be derived from Thai government organizations' realization of the negative effects of their inability to cooperate and their efforts to deal with this obstacle. This impediment, as stated in AEDP, can be resolved by searching for a host that will support the advancement of EFW programs, 
fostering integrated cooperation among relevant agencies, and developing a database system for data sharing among such entities [11,12]. The difficulty now is that Thai government organizations have not released analytical or research results on the causes of ineffective cooperation; nor have they provided details regarding the proposed improvements to collaboration or presented clearly defined steps in implementing these enhancements. This challenge points to the critical need for comprehensive explorations of the problem and systematic approaches to improving collaboration among government organizations.

Policy process generally involves different types of knowledge, actors, and activities, thus leading to situational overlaps, which inevitably drive activities in one circumstance to affect those occurring in another [13]. To this end, effective cooperation among parties is necessary for a successful public policy process [9]. As asserted by Edward [14], disunity in organizations hinders the cooperation essential to the implementation of complex policies, especially those that require joint efforts from many parties. Inappropriate institutional arrangement is indicated as a factor influencing the lack of cooperation, which in turn, contributes to ineffective policy process [15]. Hence, understanding among institutions is essential; such understanding refers to the shared concepts that govern the behavior of actors participating in a policy situations [13].

Effective cooperation should be accorded priority because many policy-related tasks required different actors to interact collectively and help one another in managing difficulties. Cooperation is also a primary driver of good understanding among actors, which can increase policy effectiveness $[16,17]$ and encourage actors to share resources, information, and competencies to support enhanced decision making, interactions, and the achievement of mutual goals and policy outcomes [18,19].

An important consideration in attempts to foster cooperation is that it is not a "simple behavior, nor even as specific pattern of behaviors. Rather, it is seen as a set of relations among behaviors and their consequences" [20]. Cooperation has been defined in different ways, but explanations of the concept always revolve around the manner by which actors effectively work together. Examples are its definitions as "the alignment of incentives, or the extent to which partners are willing to work together" [21] and "the organizations working together for the same goals, but maintain control of their individual resources" [22]. Sometimes the term "cooperation" is used interchangeably with "coordination" and "collaboration" [23,24]. Cooperation has likewise been elucidated as involving goal-directed behaviors, rewards for each participant, distributed responses, coordination, and social coordination, whose combination can augment the accuracy with which the types of cooperation transpiring among actors are classified [20].

With respect to general relationships in society, individual actors are connected with others through four types of ties, namely, (1) similarities that include "spatial and temporal proximity as well as co-membership in groups and events and sharing socially significant attributes" (e.g., residing in the same location, belonging to the same race, or having the same attitude); (2) social relations conceptualized as continuous properties (e.g., friendship, kinship, or business partnership); (3) interactions viewed as "being facilitated by and occurring in the context of social relations (and vice-versa)" (e.g., providing advice and support, engaging in trade); and (4) flows described as "tangible and intangible things that are transmitted through interactions" (e.g., information or resources) [19,25]. These ties can lead to cooperation that can occur tacitly without communication or explicit agreement given that the expectations of actors are merged; through negotiation; and through enforcement by a strong actor, provided that such actor also adjusts its own policies and endeavors to achieve mutual benefits [26]. The decision of actors to cooperate with one another is influenced by various factors, such as the previous interactions of an individual actors [20,27-29], the achievement of cooperation objectives in the past [30], the effects of institutions [13] and neighboring municipalities' decisions [31], and an actor's willingness, intensives, self-interest, and opportunism [21,32].

Because cooperation results from the decisions and actions of actors to work together, the patterns that underlie such collaboration are flexible. That is, cooperation can vary depending on the degree of interaction among actors as they jointly create values $[33,34]$. Accordingly, researchers have been 
attempting to systematically classify cooperation to broaden our understanding of this behavior. Weber and Heidenreich [33], for example, categorized cooperation in product development into vertical cooperation with suppliers and customers, horizontal cooperation with competitors, and institutional cooperation with university and research organizations. The authors also identified three stages of new product development on the basis of the actors involved in the industrial process: Concept development, product development, and implementation. Alimov [35] classified cooperation among partners, from the perspective of regional economics, into cooperation in the political and security domains, in trade and economic activities, and in the development of culture and humanitarianism. In their study on cooperation among Indonesian government organizations to support the implementation of an e-government system, Nurdin, Stockdale, and Scheepers [36] classified cooperation into vertical (within an organization) and horizontal (between different organizations) collaboration.

Effective cooperation among actors is necessary for successful collective work. To the best of our knowledge; however, a limited understanding has been achieved as to cooperation among government organizations and the conditions that are conducive to the effective development and implementation of public policy. To improve our grasp of such matters, this research delved into collaboration among Thai government organizations involved in the formulation and enactment of AEDP 2015 using the institutional analysis and development (IAD) framework. Analysis was directed specifically toward the effects of the institutions on the characteristics of policy situations, the manner by which the actors interact, and the factors that influence their decision to cooperate with one another in the policy process of interest.

The specific interactions of interest in this work were those occurring among core Thai government organizations involved in the development and implementation of the EFW targets stipulated in AEDP 2015. Data for the case study were extracted through document analysis and in-depth interviews with government staff. In this regard, the objectives of the study were to examine the intensity of cooperation among the actors and to analyze the factors and conditions that influence decisions of these actors to cooperate with one another.

To elevate our understanding of cooperation, we applied the concept of cooperation intensity, which is described as actor interactions that involve vigorous contribution to policy work and policy outcomes. The concept was further categorized into five levels to reinforce the novel contributions of this study. The levels at issue are reflected in (1) the pursuit of common goals and mutual benefits, (2) the pooling of resources, (3) the sharing of responsibilities, (4) the synchronization of activities, and (5) the monitoring of partners. This proposed hierarchy constitutes the implications of the research given its applicability as a reference in the assessment of current situations, the improvement of cooperation in a step-by-step manner, and the proposal of strategies for enhancing cooperation and, thereby, policy development and implementation.

The rest of the paper is organized as follows. Section 2 provides a brief background on the IAD framework, and Section 3 describes the methodology adopted in this work. Section 4 presents the results, Section 5 discusses the findings, and Section 6 concludes the paper.

\section{Institutional Analysis and Development Framework}

The IAD framework (Figure 1) is an institutional approach generalized for institutional and collective action analyses [13]. This framework was constructed on the basis of the effects of rules and norms that were determined from logical observations; it is useful in deriving a set of typical regulations that influence the different elements necessary for policy analysis [37,38]. The framework also uncovers details of an action situation, thereby reinforcing our understanding of interactions among actors and the outcomes of such exchanges [39]. 


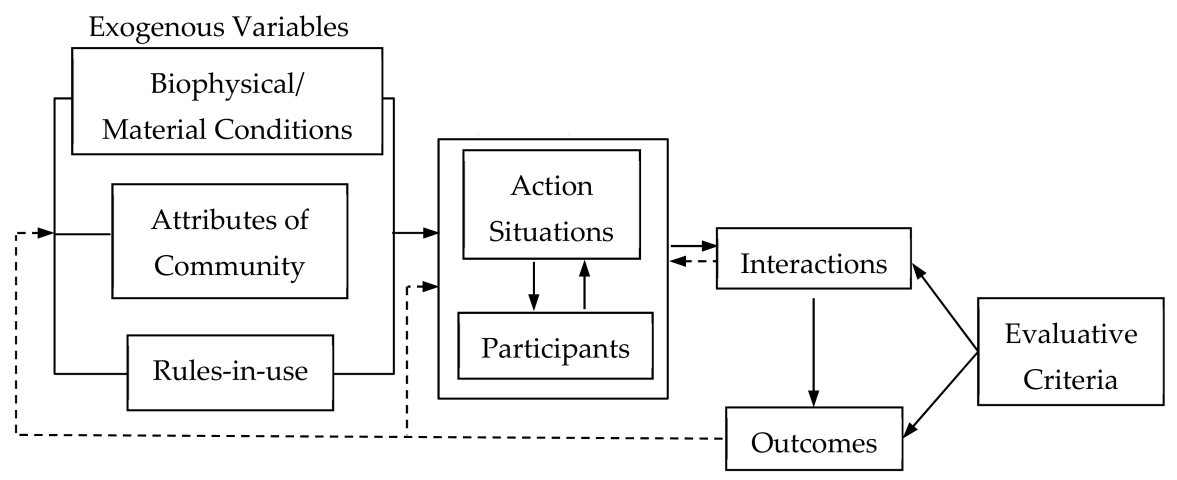

Figure 1. Institutional analytical and development (IAD) framework by Ostrom derived from [40].

The IAD framework is used to examine questions related to the effects of institutions on interesting events or situations. The framework is adopted primarily in analyzing what effects emerge from external variables, how decisions are made, and what actions are exercised [41]. Its core analytical unit is the action arena, which is defined as a conceptual space where actors interact and experience the consequences of actions [13]. The action arena comprises actors and action situations, which are influenced by exogenous variables (biophysical conditions, community attributes, and rules-in-use). The relationship between actors in an action arena that is subjected to constraints from exogenous variables are reflected through patterns of interaction [42]. An action situation is constructed from the association among seven variables, which were explained by Ostrom, Gardner, and Walker [43] as follows: When actors participate in a given situation, they are assigned positions and are required to decide among various actions in light of information made available to them. This information apprises actors of how actions are linked to potential outcomes, the levels of control that they can exercise over such linkages, and the costs and benefits that come with actions and outcomes.

The above-mentioned variables are influenced by rules-in-use, which are the "shared understanding among those involved that refer to enforced prescriptions about what actions (or states of the world) are required, prohibited, or permitted" [44]. Rules-in-use are consulted and applied by actors in action situations, thus reflecting that such regulations directly control the decisions and behaviors of actors [39]. To facilitate analysis, the IAD framework classifies rules-in-use into seven types on the basis of the key influence that they exert on variables related to an action situation [13,39,41]. These rules are presented in Table 2.

Table 2. Definitions of rules-in-use that define action arena.

\begin{tabular}{ccc}
\hline Rules & Influenced Variables & Definitions \\
\hline Boundary & Actors & $\begin{array}{r}\text { Specify how actors that are required to assume or } \\
\text { relinquish positions are chosen }\end{array}$ \\
\hline Position & Positions & $\begin{array}{c}\text { Establish a set of positions or roles, which are held by } \\
\text { different types of actors in an action situation }\end{array}$ \\
\hline Information & Actions & $\begin{array}{c}\text { Identify what actions assigned to an actor in a position are } \\
\text { allowed, mandated, and prohibited }\end{array}$ \\
\hline Aggregation & Control & $\begin{array}{c}\text { Indicate information is available to each position and } \\
\text { channels of communication among actors }\end{array}$ \\
\hline Scope & Potential outcomes & $\begin{array}{c}\text { Determine how decisions are made in an action situation } \\
\text { working backward, the actions linked to specific outcomes }\end{array}$ \\
\hline Payoff & Costs and benefits & $\begin{array}{c}\text { Affect the benefits and costs that accompany particular } \\
\text { combinations of actions and outcomes and establish } \\
\text { incentives and deterrents for action }\end{array}$ \\
\hline
\end{tabular}


The behaviors of actors who participate in a particular structure of action situations under the influence of exogenous variables constitute patterns of interaction that lead to an actual or predicted range of outcomes. Patterns of interaction are the characteristics of the internal structure that typifies an action situation and the conduct of actors in a resultant structure [13].

These components and occurrences are discernible in policy development and implementation situations, wherein one of the actions required of actors is to work cooperatively. The decision of actors to collaborate and the intensity with which they execute this task directly influences the effectiveness of policy work. Understanding the factors that affect such decisions and behavior is therefore necessary in ascertaining ways to ensure effective cooperation in policy development and implementation.

\section{Materials and Methodology}

\subsection{Qualitative Descriptive Analysis}

This study is of a qualitative design, which involves analysis grounded in qualitative descriptions for the purpose of recounting events, perceptions, experiences, or phenomena from the perspectives of informants in a simple manner $[45,46]$. The focal point of qualitative research is to obtain rich data and augment the understanding of situations evident in investigated case studies [47]. Its outstanding advantage is that the results obtained present vibrant and direct descriptions of events and perceptions, which are acquired through subtle inference. The results are interpretations that represent collected data in a language similar to an informant's own $[45,48,49]$. Adopting a qualitative descriptive design, this research thoroughly described the situations occurring in policy development and implementation on the basis of collected documentary and interview data. Information that was as rich as possible was derived without the application of strong inference to preserve the authenticity of the situations.

\subsection{Data Collection}

As previously stated, data were collected from document reviews and in-depth interviews. Print and electronic government documents related to EFW, MSW management, AEDP 2015, and related policies were analyzed (Table 3). The interview data, especially the numerical information, were rechecked against the information obtained from the documents to ensure accuracy and acquire details that might have been missed during the interviews.

Table 3. Main sources of governmental written and electronic documents.

\begin{tabular}{ccc}
\hline Governmental Documents & Year & References \\
\hline Alternative Energy Development Plan (AEDP) & 2015 & {$[8]$} \\
Action Plan for AEDP & 2015 & {$[11]$} \\
The National Solid Waste Management Master Plan & $2016-2021$ & {$[50]$} \\
Action Plan “Thai Zero Waste" & $2016-2017$ & {$[51]$} \\
Action Plan "Clean Province" & 2018 & {$[52]$} \\
Annual Report & $2015-2017$ & {$[53-55]$} \\
Thai Pollution Annual Report & 2017 & {$[56]$} \\
Booklet on Thailand State of Pollution & 2018 & {$[57]$} \\
\hline
\end{tabular}

\subsection{In-Depth Interview}

The in-depth interviews were carried out in September 2017 with nine government officials working in three ministries of the Thai government, which are Ministry of Energy (MoEN), Ministry of Natural Resources and Environment (MoNRE), and Ministry of (MoI). In accordance with the basic principles of qualitative descriptive analysis [46,47], the interviewees were thoroughly screened because this research attached more weight to the significance and richness of information than to the number of respondents. A snowball method is used to identify interviewees. All the selected interviewees were evaluated as having relevant roles, responsibilities, and solid contributions to the 
AEDP policy process and were determined as having trustworthy work experiences and specialized expertise. The interviewees were interviewed separately in Thai language at the interviewee's office with the average interview duration around 60 minutes. The interviewees were asked to explain about the situations during the development and implementation of AEDP 2015 and EFW targets with the focus on problems, difficulties, and solutions, the requirement and supports necessary for policy works, collaborative working atmosphere among relevant organizations, and the opinions about AEDP2015 and the relevant policies. The interviews results were recorded with the permissions of the interviewees. Details regarding the interviewees and their contributions to AEDP 2015 and/or EFW management are shown in Table 4.

Table 4. Details of interviewees.

\begin{tabular}{|c|c|c|}
\hline Organizations & Contributions & Number of Interviewees \\
\hline \multirow{3}{*}{ MoEN } & $\begin{array}{c}\text { Acquiring and analyzing information to set up } \\
\text { the agenda }\end{array}$ & \multirow{3}{*}{5} \\
\hline & $\begin{array}{l}\text { Comparing alternative scenarios and making } \\
\text { decisions in the formulation of AEDP } 2015\end{array}$ & \\
\hline & $\begin{array}{l}\text { Cooperating with relevant organizations to } \\
\text { implement and monitor AEDP } 2015\end{array}$ & \\
\hline \multirow{4}{*}{ MoNRE } & $\begin{array}{c}\text { Sharing information and suggestions for the } \\
\text { development of AEDP } 2015\end{array}$ & \multirow{4}{*}{2} \\
\hline & Formulating the National Solid Waste Master Plan & \\
\hline & Supporting the Zero Waste Action Plan & \\
\hline & $\begin{array}{l}\text { Approving funding for local administrative } \\
\text { organizations and EIA for EFW plants }\end{array}$ & \\
\hline \multirow{3}{*}{ MoI } & $\begin{array}{l}\text { Sharing information and suggestions for the } \\
\text { development of AEDP } 2015\end{array}$ & \multirow{3}{*}{2} \\
\hline & Operating MSW management systems & \\
\hline & Investing in EFW plants & \\
\hline
\end{tabular}

\section{Results}

The results were organized in accordance with the core analytical units of the IAD framework (exogenous variables, action arena, and patterns of interaction) - see Figure 1. The individual components of the framework were analyzed in relation to the data from the document review and interviews results.

\subsection{Analysis of Exogenous Variables}

Starting from exogenous variables, the IAD framework divides these variables into biophysical conditions, community attributes, and rules-in-use [13]. The details of these variables of the case study are presented in the following sections.

\subsubsection{Biophysical Conditions}

Polski and Ostrom [13] defined the biophysical conditions as the physical resources or capabilities involved in the production of goods or services. In the current research, the considered biophysical conditions were those pertaining to the quantity and quality of MSW available for EFW production. As stated by a MoEN interviewee, these conditions were the main concern in the establishment of EFW targets. Other conditions such as EFW locations, types of technologies, and acceptance by locals were secondary matters considering that AEDP 2015 is designed to establish national EFW targets; decisions regarding EFW investment are left to the discretion of investors.

With regard to the efforts of the MoNRE and MoI to reduce the MSW generation rate and the improper disposal of such waste in Thailand, the MoEN interviewee indicated that the ministries 
established EFW targets on the basis of the assumption that in 2036, Thailand will have inappropriately disposed of approximately 70,000 tons of MSW, among which 44,000 tons would be useable as an energy resource.

\subsubsection{Attributes of Community}

As explained by North [58] and Ostrom [41], the organizational structures, scopes of authority, and policy directions of government organizations are encompassed by governance. Similarly, the policies supporting EFW development are influenced by national agenda, which focuses on MSW management problems [59] that affect the policy directions adopted by government organizations in relation to the use and management of MSW. Amid this backdrop, these organizations are compelled to formulate policies and collaborate in serving the central government.

\subsubsection{Rules-in-Use}

This research centered on the effects of aggregation, information, and scope rules because these are the regulations that principally influence the decisions and actions of actors to interact in accomplishing policy works and outcomes.

The remaining four types of rules-in-use (boundary, position, choice, and payoff) were excluded from consideration because all the actors involved in this case study are government organizations. Their positions and actions are mandated by law and regulations, thereby eliminating the need to consider position, boundary, and choice rules. We also minimally examined payoff rules because we believe that the most important benefits obtainable by the actors are improvements to overall national social welfare [37]. We regarded actor-oriented benefits as the support and cooperation that they receive under relevant policies and costs as the increase in workload and responsibilities of actors.

The aggregation rules that influence cooperation among actors in this case study determine how decisions are made and how the effects of such decisions contribute to policy outcomes. When a government organization needs to decide on an issue, it is assumed to concern itself mainly with current situations and the value that it can offer citizens in an effort to guarantee that the decision promotes social welfare from different perspectives [37]. The nature of Thai bureaucracy means that decision-making is a centralized responsibility $[60,61]$, but efforts have been exerted to balance the demands and benefits of all stakeholders (i.e., locals, authorities, private sectors, and NGOs) during a policy process. Such balance is realized through public hearings, discussions featuring expert panels, and focus group meetings, wherein various types of feedbacks and recommendations are elicited. Nonetheless, even though the Thai government has been gradually leaning toward a balance-oriented approach, its key concern remains the avoidance of decisions that cause conflicts, tensions, and increased workload for officials because these can offend other organizations [61,62].

Information rules affect the availability of information and communication channels. The actors in this case study communicate and share information through formal channels, such as official correspondence, questionnaires, and discussions. However, the interview results indicated that the actors disclose certain information in accordance with how convenient and confident they feel about it. Some data that need to be divulged, such as information processing methods, are therefore concealed. This behavior was explained by Velayutham and Perera [63] as originating from a shame-prone culture, which drives government sectors to avoid disclosing information pertaining to themselves. Consequently, it is difficult for actors to adequately obtain the information that they require.

Scope rules specify the extent of outcomes that can be influenced and whether desired outcomes are achieved. Potential outcomes are the consequences of an actor's decisions to implement actions given the availability of certain information. For this reason, when the MoEN evaluates potential policy outcomes with limited information as foundation, path dependency is used to delimit results that are affected by actions. Path dependency refers to decisions that are made on the basis of past knowledge and situations. The MoEN believes that ensuring the completion of policy works necessitates adjustments to AEDP 2015 targets in accordance with related policies that were established 
before the issuance of this version of the plan. These adjustments are expected to clear the way for gaining the support and cooperation of other actors.

\subsection{Analysis of Acton Arena}

Actors and action situations are two action arena components that need to be identified to illustrate the conditions lead to interactions in the considering situations. In this study, all the actors examined are government organizations (i.e., the MoEN, MoNRE, and MoI) who functioned as the key players in policy development and implementation situations. Feedbacks from various stakeholders, such as locals, authorities, private sector companies, and NGOs, obtained through public hearing activities, were treated as information that required consideration by government organizations under the policy development and implementation process. The two components are explained in detail in the succeeding sections.

\subsubsection{Actors}

Because of the research's concentration on policy development and implementation by government organizations, three major government actors were analyzed. The first is the MoNRE, which is in charge of regulating the MSW generation rate and promoting the conversion of such waste into energy. The second actor is the MoI, which manages and controls Thailand's waste management system (WMS) and decides on how to treat collected MSW. The third actor is the MoEN, which creates incentives and encourages the development of and investment in EFW. Each of these actors operate under different conditions in effectively developing and implementing policy because they also use varying skills, resources, and processes under policy process (see [64]).

\subsubsection{Action Situation}

The action situation of interest in this work was explored with reference to the variables related to an action arena, as proposed in the IAD framework. Given that all the actors examined are government organization, their roles, scopes of authority, and responsibilities were delineated. Under the IAD framework, two types of information are necessary for analysis: Complete and perfect information [41]. When actors have complete information, they know about the internal structure of the action situations in which they participate (actors, positions, actions, control, potential outcomes, and costs and benefits) [41]. This does not mean, however, that they have perfect information, which is the kind of information that enables actors to determine what happened in the past and how their partners will move in the future [41].

In this study, all the actors were assumed to have the same complete information about the internal structures (actors, positions, actions, controls, potential outcomes, and costs and benefits) that characterize situations. Nevertheless, their abilities in analyzing and interpreting such information can differ. Another essential issue for consideration is whether the actors have perfect information given that this affects decisions. Tables 5 and 6 present details regarding the internal structure of the AEDP 2015 development and implementation processes.

1. AEDP 2015 development process

The ongoing development of AEDP 2015 includes agenda-setting, decision-making, and policy formulation. The interviews showed that the main actor in this process is the MoEN as this is the agency responsible for establishing the development plan. Its core mandates are identifying problems, comparing alternative solutions, discussing policy directions and targets, and formulating policy. The MoNRE and MoI participate in the policy development process as consultants that are required to share information, especially on the MSW generation rate and capacity of the WMS; exchange ideas, comments, and suggestions; and discuss policy direction and targets. Although the information, ideas, and suggestions provided by the MoNRE and MoI are important and can influence the EFW context, control over EFW targets remains with the MoEN. 
With respect to potential outcomes/consequences of actions, the measures carried out by the MoNRE and MoI can result in a renewable energy policy that is consistent with the MSW policies. The MoNRE and MoI are obligated to add to their works, but they can also gain benefits from a renewable energy policy that promotes the provision of support and incentives for MSW policies. The vastness of the MSW generated in Thailand translates to a critical burden on landfilling, but conversion into EFW is expected to reduce the volume that the country has to contend with. Simultaneously, the MoEN's actions lead to achievable EFW targets and attractive incentives for stakeholders, thereby enabling the ministry to acquire assistance and cooperation for EFW development and investment.

Table 5. Internal structure of policy development situation on the basis of actors.

\begin{tabular}{|c|c|c|}
\hline \multirow{2}{*}{$\begin{array}{c}\text { Variables } \\
\text { Actors }\end{array}$} & \multicolumn{2}{|c|}{ Internal Structure vis-à-vis Individual Actors } \\
\hline & MoEN & MoNRE \\
\hline Positions & Policy maker & Policy consultant \\
\hline Actions & $\begin{array}{ll}\text { - } & \text { Identify problems } \\
\text { - } & \text { Compare } \\
\text { - } & \text { alternative solutions } \\
\text { - } & \text { Allow MoNmulate policy } \\
\text { discuss policy directions } \\
\text { and targets }\end{array}$ & $\begin{array}{l}\text { - } \quad \text { Provide required information } \\
\text { - Share ideas, comments, and suggestions }\end{array}$ \\
\hline
\end{tabular}

\begin{tabular}{ccc}
\hline Information & \multicolumn{2}{c}{ Complete, but not perfect information } \\
\hline Control & Full effect on EFW target setting & Partial effect on EFW target setting \\
\hline Potential outcomes & $\begin{array}{c}\text { Achievable EFW targets and } \\
\text { attractive incentives for all } \\
\text { stakeholders }\end{array}$ & $\begin{array}{c}\text { Renewable energy development policy consistent } \\
\text { with MSW policies }\end{array}$ \\
\hline Costs and benefits & $\begin{array}{c}\text { Support and cooperation for EFW } \\
\text { development and implementation }\end{array}$ & $\begin{array}{c}\text { Increased workload } \\
\text { Support and incentives for converting MSW } \\
\text { into EFW }\end{array}$ \\
\hline
\end{tabular}

\section{AEDP 2015 implementation process}

Implementing AEDP 2015 to achieve EFW targets necessitates that the three actors work collectively and cooperatively. The MoEN is the actor mandated to ensure policy success, the MoI is the key actor who can drive EFW development and investment, and the MoNRE is a critical agent involved in environmental impact assessment (EIA) approval of the construction of EFW plants.

In this process, the MoEN has partial control over the goal achievement because it serves as a consultant, grants approval for financial support and incentives, and policy monitor. Contrastingly, the MoI enjoys greater jurisdiction because it acts as a policy operator and investor who can decide on investments and select MSW treatment options. Similar to the MoEN, the MoNRE can influence EFW development to a limited extent owing to its functions as a consultant, supporter, and EIA endorser that can facilitate the EIA application and approval as well as provide knowledge about EFW and related technologies.

With regards to potential outcomes from individual actors, the actions of the MoEN foster interest in EFW development, which in turn, advances the realization of policy targets. When the MoEN monitors implementation results, it can ascertain achieved and unachieved targets, thereby paving the way for dealing with unexpected results. The potential outcomes of MoNRE actions are convenience in EIA applications and increased interest in EFW development and investment. Although the MoNRE is compelled to work exhaustively in adjusting the EIA approval process, it gains support for MSW solutions. The possible end result obtainable by the MoI is increased investment in the conversion 
of MSW into EFW products-a development that is advantageous to the reduction of landfilling, the production of electricity or heat from MSW, and the acquisition of financial support.

Table 6. Internal structure of policy implementation situation on the basis of actors.

\begin{tabular}{|c|c|c|c|}
\hline Variables & \multicolumn{3}{|c|}{ Internal Structure vis-à-vis Individual Actors } \\
\hline Actors & MoEN & MoNRE & MoI \\
\hline Positions & $\begin{array}{l}\text { Incentive and support endorser, } \\
\text { consultant, and policy monitor }\end{array}$ & $\begin{array}{l}\text { EIA endorser, consultant and } \\
\text { supporter }\end{array}$ & Policy operator and investor \\
\hline Actions & 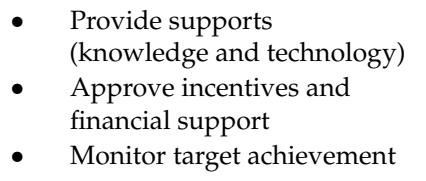 & $\begin{array}{ll}\text { - } & \text { Approve EIA for EFW plant } \\
\text { Provide supports } \\
\text { (knowledge and technology) }\end{array}$ & $\begin{array}{l}\text { Select treatment for } \\
\text { collected MSW } \\
\text { Decide to invest in } \\
\text { EFW plants }\end{array}$ \\
\hline Information & \multicolumn{3}{|c|}{ Complete, but not perfect information } \\
\hline Control & $\begin{array}{c}\text { Partial impact on EFW target } \\
\text { achievement }\end{array}$ & $\begin{array}{c}\text { Partial impact on EFW target } \\
\text { achievement }\end{array}$ & $\begin{array}{c}\text { Major impact on EFW target } \\
\text { achievement }\end{array}$ \\
\hline Potential outcomes & $\begin{array}{l}\text { Increased interest in EFW } \\
\text { development and investment }\end{array}$ & $\begin{array}{l}\text { - Convenience in applying for } \\
\text { EIA approval } \\
\text { - Increased interest in EFW } \\
\text { development and investment }\end{array}$ & Increase in EFW investment \\
\hline Costs and benefits & $\begin{array}{l}\text { - } \quad \text { EFW target achievement } \\
\text { Information to deal with } \\
\text { unexpected outcomes }\end{array}$ & $\begin{array}{ll}\text { - } & \text { Increased workload } \\
\text { - } & \text { Support for MSW policy }\end{array}$ & $\begin{array}{ll}\text { - } & \text { Reduction of landfilling } \\
\text { - } & \text { Energy in the form of } \\
\text { electricity or heat } \\
\text { - } & \text { Financial support }\end{array}$ \\
\hline
\end{tabular}

Concerning the benefits obtained from the successful implementation of AEDP 2015, the average cost of renewable energy production based on the levelized cost of energy (LCOE) is forecasted to reach 17.4 million baht/ktoe, and the average price of fossil fuels is estimated at 15 million baht/ktoe $[8,11]$. However, the advantages that Thailand is expected to gain in terms of the mitigation of GHG emission through the use of renewable energy for electricity and heat generation are is 2350 and $4120 \mathrm{tCO}_{2 \mathrm{eq}} / \mathrm{ktoe}$, respectively [11]. Additionally, around 16,060,000 tons of MSW per year is used to produce energy rather than having such waste sent to landfills or treated through other methods. Aracil et al. [65] estimated that landfill treatment for a ton of MSW can produce $0.454 \mathrm{tCO}_{2 \mathrm{eq}}$ of GHG emissions, indicating

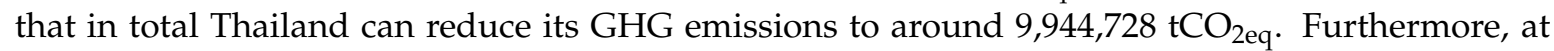
a carbon credit price of $300 \mathrm{baht} / \mathrm{tCO}_{2 \mathrm{eq}}$ [66], Thailand can acquire additional benefits valued at 1,168,346,000 baht. The projected costs and benefits of AEDP 2015 are summarized in Table 7.

Table 7. Costs and benefits of achieving energy-from-waste (EFW) targets in 2036.

\begin{tabular}{|c|c|c|c|c|}
\hline \multicolumn{2}{|r|}{ Costs and Benefits } & Million Baht & Million USD * & \multirow{2}{*}{$\begin{array}{c}\text { Calculations } \\
\begin{array}{c}756.28^{* *} \text { ktoe } \times 17.4 \text { million } \\
\text { Baht } / \text { ktoe }\end{array}\end{array}$} \\
\hline Costs & EFW production & $13,159.27$ & 438.64 & \\
\hline \multirow{5}{*}{ Benefits } & Total costs & $13,159.27$ & 438.64 & \multirow{5}{*}{$\begin{array}{c}756.28^{* *} \text { ktoe } \times 15 \text { million } \\
\text { Baht } / \text { ktoe } \\
{\left[\left(261.28^{* *} \text { ktoe } \times 2350\right.\right.} \\
\left.\mathrm{tCO}_{2 \mathrm{eq}} / \mathrm{ktoe}\right)+(495 * \text { ktoe } \times 4120 \\
\left.\left.\mathrm{tCO}_{2 \mathrm{eq}} / \mathrm{ktoe}\right)\right] \times 300 \mathrm{Baht} / \mathrm{t} \mathrm{tCO}_{2 \mathrm{eq}} \\
44,000 \mathrm{tMSW} / \text { day } \times 365 \text { days } \times \\
0.454 \mathrm{tCO}_{2 \mathrm{eq}} / \mathrm{tMSW} \times 300 \text { Baht } / \\
\mathrm{tCO}_{2 \mathrm{eq}}\end{array}$} \\
\hline & - $\quad$ Replacing fossil fuels usage & $11,344.20$ & 378.14 & \\
\hline & $\begin{array}{ll}\text { by EFW } \\
\text { Reduction of GHG } \\
\text { emission from replacing } \\
\text { fossil fuels by EFW }\end{array}$ & 796.05 & 26.53 & \\
\hline & $\begin{array}{l}\text { - Reduction of GHG in MSW } \\
\text { treatment in landfills }\end{array}$ & 2187.37 & 72.91 & \\
\hline & Total benefits & $14,327.62$ & 477.58 & \\
\hline & Total Benefits & 1168.35 & 38.94 & $\begin{array}{l}\text { 14,327.62 million baht-13,159.27 } \\
\text { million baht }\end{array}$ \\
\hline
\end{tabular}

Notes: ${ }^{*} 1$ USD $=30$ baht. ${ }^{* *}$ An electricity generation of $500 \mathrm{MW}$ is equal to 261.28 ktoe [11]. The total EFW target is 261.28 ktoe of electricity +495 ktoe of heat $=756.28$ ktoe. 


\subsection{Analysis of Patterns of Interaction}

\subsubsection{Classification of the Cooperation Intensity}

Park, Srivastava, and Gnyawali [34] and Weber and Heidenreich [33] asserted that the degrees to which an actor cooperates with its partners can vary across different partners and periods of time; these aspects relate to the conditions that characterize a situation. The authors regarded these extents of interaction as reflective of the intensity of cooperation. This explanation motivated the current research to classify patterns of cooperation in the AEDP policy process into different levels of cooperation intensity given that cooperation is the result of varying scales of an actor's decision to interact or work with another. In consonance with this approach, we defined the intensity of cooperation as actor interaction that involves vigorous contribution to policy works and outcomes. The levels of cooperation intensity in the AEDP policy process are reflected in an actor's decision to; cooperate by (1) pursuing common goals and mutual benefits, (2) pooling resources, (3) sharing responsibility, (4) synchronizing activities, and (5) monitoring partners. Each level of cooperation intensity is described as follows.

First, the pursuing of common goals and mutual benefits is the initial level of cooperation intensity occurring among actors. The goal-directed behaviors and rewards of actors are important stimuli of cooperation because actors cooperate to create mutual value together [20,33]. Benefits are equally important prerequisites for cooperation [67]. Nevertheless, different goals or needs can act as barriers as they may obstruct the advancement of common goals among actors [19,68].

In the current research, two types of goals in a policy process are considered and adopted. The first are system goals, which relate to "the characteristics of the system as a whole" and the second are derived goals, which refers to "the uses to which power generated by organization activities can be put" [69].

Goal- and benefit-induced cooperation can also occur tacitly [26], in which case actors work toward the same general objectives but each interacting individually to accomplish its own goals and maintain control of its own resources [22]. In simple terms, actors espouse the same system goals but do not necessarily pursue derived goals that translate to support among actors. However, individual actors can still acquire benefits from related policies that do not impede another.

Alternatively, when actors cooperate in pursuing common goals and mutual benefits that are obtained through negotiation and communication, all actors perceive situations, problems, and the resolution directions congruently. Ideally, all derived goals are set consistently, thus serving both the system goals and the derived goals of others.

When actors understand situations and partners well enough, they willingly agree to commit to collaboratively solving problems that cannot be rectified individually. In this situation, all actors band together, remain dedicated, and cooperate by devoting resources to problem resolution [70]. The upshot of all these is the second level of cooperation intensity.

Second, the pooling of resources occurs when actors combine their resources to overcome the limitations encountered in satisfying the resources necessary in joint policy works. Resources should be pooled openly and systematically, and actors should keep in mind that the blended resources are now designed to the benefit the public, with such resources belonging to everyone. Although resource pooling facilitates a smooth policy workflow, some actors can be compelled to share cherished resources and/or disclose sensitive information.

The combination of resources can solve certain problems, such as information and human resource shortage, but an important requirement is for actors to work collectively in competing policy works; that is, all actors should cooperate to ensure successful policy initiatives. These actions demand a higher level of cooperation intensity-a requirement that can be satisfied through the sharing of responsibilities.

Third, the sharing of responsibilities among actors leads such actors to be accountable together or share the blame for outcomes. Here, responsibilities are considered as tasks that actors are obligated to accomplished [71]. At this level of cooperation intensity, certain actors should be authorized as representatives, whereas others should be instructed to work in concert in eliminating constraints and 
difficulties [72,73] and thereby advance a smooth workflow. Cooperation is the result of joint efforts that are motivated by a good working relationship among actors [74], but such agents are inevitable affected by others' unpleasant behaviors and results. At this intensity, therefore, perfect information becomes necessary for cooperative decision making.

To share responsibilities systematically, actors must clarify duties and roles, with a view to addressing overlaps. When actors concertedly bear obligations, they are mutually working toward policy targets. An essential component, therefore, is assigning responsibilities that match an actor's actions and control over outcomes. This level of cooperation can lead to the integration of relevant policies among actors, which brings us to the fourth level of cooperation intensity.

Fourth, the synchronization of policy activities for the achievement of effective and sustainable cooperation. Without such coordination, it is difficult for actors to achieve successful cooperation [20].

Synchronized activities prompt improved policy outcomes [75], which are the results of the effective policy process. Duplicate policy activities should be pinpointed and synchronized, and collective policy affairs should be organized consistently to cultivate a lean policy process and conserve resources. It is important to remember, however, that the synchronization of policy activities can affect the control that actors can wield over policy works and outcomes. Because actors are required to cooperate with others to support and conduct activities together, critical tasks are for all actors to plan and agree on how tis cooperation intensity is to be approached and implemented. Moreover, the synchronization of activities intensifies the involvement of other actors, underscoring the necessity of ensuring systematic and effective cooperation. As noted by Ajzen [76], that if actors consider a situation unmanageable or if they have insufficient control over actions, the likelihood of cooperation can diminish.

It is inevitable that when actors cooperate with others, they monitor the behaviors and interactions of those with which they collaborate [20]. Systematic and formal monitoring is essential to strengthen the intensity of cooperation.

Fifth, the monitoring of partner is considered the highest cooperation intensity in a policy process because its initiation requires close coordination and involvement among actors. At this level of cooperation, actors can check the decisions and actions implemented by their partners and share monitoring results with one another. In doing so, they can solve problems and plan preventive measures together. Note that partners should monitor one another in an unbiased fashion to ensure that all actors interact purposefully and harmoniously under limited resources and to guarantee that work redundancy is minimized. Although monitoring might render work and decision making, actors should willingly undergo scrutiny.

Systematic and formal monitoring is important in enriching policy works and outcomes because it facilitates an effective policy process. An issue that must be emphasized, however, is that actors should not monitor their partners as a means of fault-finding but as a guarantee of the successful achievement of the common goals. The concerted effort toward goal achievement is the fundamental factor that triggers cooperation among actors under a policy process.

To facilitate the examination of cooperation intensity among government organizations in a policy process, this research identified general attributes of the seven internal structure variables of an action arena (Table 8). Because the evaluated actors are government organizations who occupy different positions in the AEDP policy process, they were assumed to have complete information about the action arena. Note that a high level of cooperation intensity necessitates perfect information. 
Table 8. Comparison of the internal structure of the action situation at different cooperation intensities.

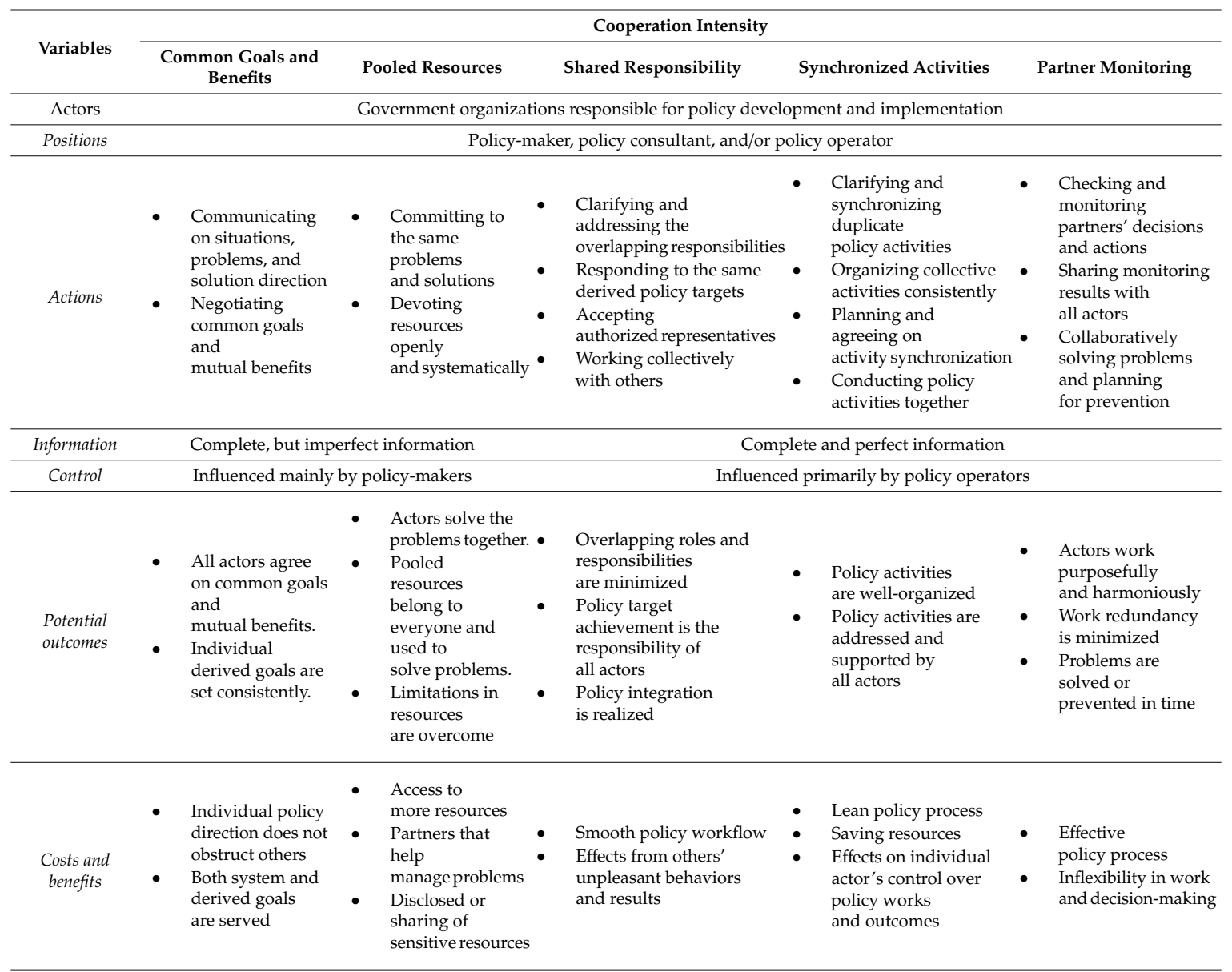

4.3.2. Intensity of Cooperation under the Policy Process of AEDP 2015

1. The proposed levels of cooperation intensity were adopted in the exploration of cooperation in the policy development and implementation of interest in this work. Policy development

In the development of EFW targets for AEDP 2015, the MoEN plays the most important role as a decision maker that is accorded full power to decide on and formulate policy. The MoNRE and MoI are involved principally as policy consultants who share information, suggestions, and knowledge required by the MoEN.

Considering the intensity of cooperation in the development of AEDP 2015, all the actors share a common goal in solving problems caused by MSW and will gain mutual benefits in serving the national agenda when the goal is achieved. Therefore, actors can use commonality in goals and benefits as a reference when deciding on whether or not cooperate with other parties. This is considered a good starting point for further cooperation given that all actors agree on a single direction. Nevertheless, it is important to note that individual actors are still committed to their own policies, which are regarded as different derived goals.

As demonstrated by the interview results, the MoEN's derived goals lie in the conversion of MSW into EFW, as stated in the AEDP 2015 targets. The derived goals of the MoNRE are to reduce MSW generation and increase sanitation in MSW treatment, but the ministry views EFW as a by-product of MSW reuse and recycling. For the MoI, a derived goal is the reduction of organic waste at dump sites, driving it to focus on encouraging people to separate organic waste and use it as a fertilizer. All these actors try to solve the MSW problems experienced by Thailand, but variances in their derived 
goals have given rise to different solutions-a situation that can hinder elevation to a stronger level of cooperation for a particular policy.

During the development of EFW targets, the MoEN required cooperation from the MoNRE and MoI in pooling resources, especially information about MSW management. The interview findings uncovered that even though the two aforementioned actors shared ideas and information with the MoEN, they did not openly accomplish this task and acted similar to outsiders that do not near responsibility for the success of AEDP 2015. This discrepancy in commitment was further compounded by varying EFW priorities, as reflected in the ministries' derived goals. As a result, the MoNRE and MoI did not see necessity of the information sharing, which in turn affected the pooling of resources and impeded the movement toward increased cooperation intensity.

Cooperation through the sharing of responsibilities among the actors is not easily discernible, but the MoEN staff have attempted such sharing with the MoNRE by setting up action plans in as much accordance as possible with the National Solid Waste Master Plan. The interviewees explained that when problems occur, all relevant actors should concertedly assume accountability for solving problems.

During the development of AEDP 2015, one of the most important activities were public hearings. The interview stated that individual actors conducted these events separately possibly because of differences in the timing of policy development and the duration of policy implementation. Had relevant policies been integrated, the actors could have at least synchronized their public hearing activities. This synchronization would have enabled them to acquire various views and comments on MSW problems and solutions and, in the end, analyze the situation together and identify solutions holistically.

In the matter of partner monitoring, because the AEDP 2015 development is the sole responsibility of the MoEN, such checks and balances were not mentioned by interviewees.

2. Policy implementation

Achieving EFW targets under AEDP 2015 implementation necessitates the establishment of collective waste collection centers, whose construction is the responsibility of the MoI with support from the MoNRE.

In this respect, the actors still pursue the same common goals and benefits seeing as such elements cascaded from the development of AEDP 2015. However, the MoNRE and MoI continue to be devoted to the implementation of their own policies.

Another significant strategy is motivating the MoI and the private sector to invest in EFW plants. In keeping with this approach, the MoEN provides incentives to investors and cooperates with the MoNRE in sharing knowledge and information on EFW technologies to interested parties.

In the implementation of AEDP 2015, the actors do not fully shoulder responsibilities as a team. As mentioned previously, the building of the collective waste collection centers is the responsibility of the MoI, which is aided by the MoNRE in terms of ensuring feasibilities, knowledge, and information about technologies and investments. The MoNRE also supports the MoEN in research and development for EFW technologies and production.

Similar to the synchronization of activities, cooperation intensity at this level is imperceptible. Cooperation among the actors, in its current form, is limited to linking activities for EFW investment owing to the MoEN's encouragement of the MoI, through inducements, to convert collected MSW into energy and the MoNRE's facilitations of the EIA process through a reduction of the time spent on the approval process.

The interviewees indicated that the actors failed to fully monitor one another given the inflexibility and suspicion of fault-finding actors; against this backdrop, no one took the monitoring process seriously. Employees of the MoEN and MoNRE stated that they simply monitor policy implementation results because they do not have the right or authority to force or push others to accomplish policy works. Furthermore, no formal and effective monitoring system is implemented by the actors. The sluggishness in developing an effective monitoring system may be attributed to the unwillingness of actor to be subjected to scrutiny. Table 9 compares the ideal situation for each level of cooperation intensity with 
the actual cooperation occurring during the AEDP 2015 development and implementation. The causes of the gaps between ideal and actual cooperation are discussed in the succeeding section.

Table 9. Comparison of ideal and actual cooperate in the AEDP 2015 development and implementation.

\begin{tabular}{|c|c|c|c|}
\hline \multirow{2}{*}{ Cooperation Intensity } & \multirow{2}{*}{ Ideal Situation } & \multicolumn{2}{|c|}{ Actual Situation } \\
\hline & & Policy Development & Policy Implementation \\
\hline $\begin{array}{l}\text { Common goals and } \\
\text { mutual benefits }\end{array}$ & $\begin{array}{l}\text { Actors have similar common } \\
\text { goals and consistent derived } \\
\text { goals that support } \\
\text { one another. } \\
\text { Problem responses and } \\
\text { solutions are prioritized in } \\
\text { the same direction } \\
\text { All actors agree on and } \\
\text { satisfy mutual benefits. }\end{array}$ & $\begin{array}{l}\text { - Actors have common goals } \\
\text { in solving MSW problems, } \\
\text { but they see and prioritize } \\
\text { problems and } \\
\text { solutions differently } \\
\text { Actors agree on mutual } \\
\text { benefits in serving the } \\
\text { national agenda, but their } \\
\text { satisfaction is doubtful }\end{array}$ & - \\
\hline Pooled resources & $\begin{array}{l}\text { - Actors are committed to } \\
\text { problem solving and are } \\
\text { concerned with public } \\
\text { benefits more than } \\
\text { individual benefits } \\
\text { Resources are combined } \\
\text { openly and systematically } \\
\text { Pooled resources are devoted } \\
\text { to the public and belong to } \\
\text { all actors. }\end{array}$ & $\begin{array}{l}\text { Actors are not committed } \\
\text { to the same solutions. } \\
\text { Information is not pooled } \\
\text { openly. Actors are still } \\
\text { concerned about the } \\
\text { possible negative } \\
\text { consequences of fully } \\
\text { disclosing information. }\end{array}$ & - \\
\hline Shared responsibilities & 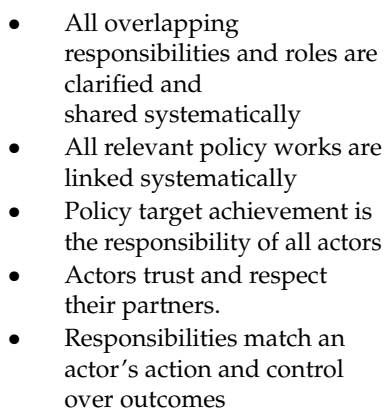 & $\begin{array}{l}\text { - MoEN has tried to link } \\
\text { policy works with others } \\
\text { by adjusting EFW targets } \\
\text { in accordance with the } \\
\text { related policies that } \\
\text { were launched. } \\
\text { Mismatch requires action } \\
\text { and control over the } \\
\text { outcomes of MoNRE and } \\
\text { MoI in the policy } \\
\text { development process }\end{array}$ & $\begin{array}{l}\text { - } \quad \text { No policy targets are } \\
\text { assumed by actors. } \\
\text { Some roles and } \\
\text { responsibilities are } \\
\text { still overlapping } \\
\text { - } \quad \text { Each actor is responsible for } \\
\text { its own policy only } \\
\text { There is a mismatch in MoI } \\
\text { responsibilities and actions } \\
\text { intended to support the EFW } \\
\text { development } \\
\text { and investment. }\end{array}$ \\
\hline Synchronized activities & $\begin{array}{l}\text { - All actors work and agree on } \\
\text { the synchronization of } \\
\text { policy activities } \\
\text { - } \quad \text { All duplicate activities are } \\
\text { clarified and synchronized } \\
\text { - } \quad \text { Collective policy activities } \\
\text { are organized } \\
\text { - Actors support and conduct } \\
\text { synchronized } \\
\text { policy activities }\end{array}$ & $\begin{array}{l}\text { - No plan to clarify and } \\
\text { synchronize the related } \\
\text { policy activities formally }\end{array}$ & $\begin{array}{ll}\text { - } & \text { Many activities } \\
\text { remain duplicated } \\
\text { - } \quad \text { Policy activities are } \\
\text { conducted separately }\end{array}$ \\
\hline Partner monitoring & $\begin{array}{l}\text { Actors monitor their partners } \\
\text { without bias to ensure the } \\
\text { effectiveness of policy } \\
\text { workflow, not } \\
\text { for fault-finding. } \\
\text { - Actors are willing to let } \\
\text { others check and monitor } \\
\text { their work. } \\
\text { A formal and effective } \\
\text { monitoring system is } \\
\text { in place. }\end{array}$ & - & $\begin{array}{l}\text { - No formal and effective } \\
\text { monitoring system is } \\
\text { in place. } \\
\text { - Actors monitor the outcomes } \\
\text { after the completion of } \\
\text { activities or processes. } \\
\text { - Actors are unwilling to be } \\
\text { checked and monitored. }\end{array}$ \\
\hline
\end{tabular}




\section{Discussion}

In different countries, policies visibly exert a significant influence on the development of renewable energy and investment in this resource; therefore, active involvement and effective cooperation among relevant actors are the major precondition for the transition to renewable energy utilization [4]. To this end, this study focused on the examination of cooperation among actors under a policy process as reflective of patterns of interaction that relate to the behaviors of actors and the consequences of such conduct on expected policy outcomes [20]. Park, Srivastava, and Gnyawali [34] classified the different degrees to which actors cooperate with their partners given that the extent of collaboration can vary depending on partners and period of time [33]. This concept was adopted in the present study, this time to classify cooperation in the AEDP policy process, and the intensity of cooperation was defined as actor interactions that entail intensive contributions to policy works and outcomes. Correspondingly, five levels of cooperation intensity were conceptualized; collaboration through (1) the pursuit of common goals and mutual benefits, (2) the pooling of resources, (3) the sharing of responsibilities, (4) the synchronization of activities, and (5) the monitoring of partners. This cooperation hierarchy can be used as a guide in analyzing current and future (projected) cooperation and advancing enhanced collaboration.

We applied the proposed cooperation intensity levels to the case study (Table 9) and found that the main gaps between ideal and actual interactions are (1) differences in perceptions of MSW problems and the prioritization of the solutions put forward by individual actors; (2) the actors' commitment to the different solutions; (3) inconsistency among responsibilities, actions, and control over the outcomes of the actors; (4) the failure of the actors to clarify and synchronize related and duplicate policy activities; and (5) the unwillingness of the actors to undergo checking and monitoring.

This study likewise identified and scrutinized the variables that influence the gaps between ideal and actual cooperation in the case study. This objective was accomplished by probing into different cooperation intensity levels during the AEDP policy development and implementation on the basis of ideal action arena structures (Table 8). The gap in cooperation intensity with respect to common goals and mutual benefits is caused by variances between ideal and actual actions. The actors do not clearly communicate individual views regarding MSW problems and solution directions. This deficient communication drives the actors to solve national MSW challenges in different ways, as reflected in the inconsistency of their derived goals. With regard to resource pooling, the actors also pursue divergent solutions, thereby affecting potential outcomes and causing difficulties in combining resources.

Before considering the variables that influence the gaps in the rest of the cooperation intensity levels, it should be noted that the actors do not have perfect information, which is the ideal variable in the action arena for shared responsibilities, synchronized activities, and partner monitoring. Information is a critical source of gaps because the actors are compelled to decide and act under inadequate information.

Gaps in shared responsibilities are caused by actions, potential outcomes, and control variables. In the case study, the actors do not implement effective actions in clarifying overlapped responsibilities and thus respond to varying policy targets. This affects the balance of control given that the MoEN is the sole agent responsible for the achievement of AEDP 2015 targets, whereas the MoI is the policy operator who oversees the selection of MSW treatment approaches. Additionally, activities are not synchronized because the actors neither plan for such integrating nor organize policy activities together. In the matter of partner monitoring, the Thai government experiences difficulty in accomplishing this aspect of cooperation given that action arena variables (i.e., actions, information, control, potential outcomes, and costs and benefits) have yet to be constructed. Currently, no effective monitoring system under Thai bureaucracy is in place, and the actors themselves are unwilling to undergo checking and monitoring because of the inflexibility, suspicion, and fault-finding to which actors resort when mistakes are made.

According to Smajgl, Leitch, and Lynam [75], all action arenas are influenced by the rules-in-use. In the IAD framework, rules-in-use include both formal and informal rules that significantly impact an action arena [41]. This study investigated aggregation, information, and scope rules that chiefly affect 
the actors' decisions and consequent outcomes. The effects of these rules on action arena variables were used to explain the decisions, actions, and behaviors of the actors involved in the case study. Because all the actors are government organizations, formal rules are enacted as laws or regulations. Focus therefore, revolved around the informal rules that are molded by norms and behaviors [76]. Informal rules can be combined with formal ones, which can then restrict how actors interact and make decisions.

In consideration of different rules under the category of information rules, the one that most essentially affects the information variable in the action arena is the shame-prone culture that discourages the disclosure of sensitive information [63]. This rule prevents actors from acquiring perfect information, which is necessary for movement toward a higher cooperation intensity. Limited information affects actors' decisions seeing as they are forced to decide with inadequate knowledge as a basis. Elevation to more intense cooperation is likewise impeded by the control variable that is governed by the rule on avoiding decisions that can cause conflicts, tensions, and, particularly, increased workload among actors [61,62]. This rule is categorized as of aggregate type, specifying how actors decide over choices. When actors' decision-making hinges on the desire to avoid conflicts, tensions, and increased workload, potential outcomes can be constrained. The potential outcome variable is controlled by scope rules. In the case study, the most important scope rule is path dependency. Given that the MoEN faces imperfect information and is constrained by the avoidance of conflicts, tensions, and increased workload for its partner, it is obligated to forecast potential outcomes on the basis of path dependency. Cooperation intensity in the case study is low; thus, predicting potential outcomes with past situations as basis is inevitable, although a higher cooperation intensity in the future might be deterred.

As patterns of cooperation are influenced by an action arena and variables in the action arena are influenced by rules-in-use, theoretically, changing the latter should result in a more appropriate internal action arena structure, which should improve the patterns of that underlie cooperation among Thai government organizations. For example, when actors make decisions, they should concern themselves with elevating the quality of national social welfare rather than devoting resources to circumventing conflicts, tensions, or increased employee workload. This does not mean, however, that actors should be aggressive and inflexible; rather, they should decide sincerely and reasonably for the benefit of the country. Moreover, adherence to the shame-prone culture should stop because it is a tremendous obstacle not only to advancement to more intense cooperation but also to the development of an entire policy process.

Notwithstanding the potential advantage of altering rules-in-use, especially informal ones, such strategy is not easy and takes time. In practice, adjusting some variables in an action arena can be more easily and more rapidly achieved. Actors evaluate situations differently, and they work under diverse conditions; an essential requirement, then, is to fine-tune understanding among actors. Consistent with this requirement, this research recommends obligating all actors to thoroughly communicate with their partners at every cooperation intensity as good understanding among actors, especially with regards to individual needs and limitations, is crucial to collaboration and improvements to cooperation intensity in the future. Because Thai government organizations evaluated their performance twice a year, the satisfaction of their partners with communication should be used as a performance criterion. As van Karnenbeek and Janssen-Jansen [76] explained, informal rules are "the rules that are shaped by norms and behavior". Therefore, when actors communicate intensively, they gradually become accustomed to this behavior, which slowly becomes the norm for them. Consequently, intensive communication during collaboration in a policy process can serve as the rules that drives the actions of government organizations in the future.

As Chenboonthai and Watanabe [64] examined government organizations as actors in an action arena and explained that because actors value their own policy capacities (i.e., the conditions conducive to policy development and implementation) and those of others differently, they face difficulties in cooperating during policy works. In the present research, the effects of the internal structure of an action situation in an action arena on patterns of cooperation were investigated, along with the effects of the rules-in-use on the variables of the action situation. Ineffective cooperation is influenced not 
only by the different valuations of actor's policy capacities, but also by inappropriate internal action arena structures, which might be controlled by rules-in-use. As a result, understanding the policy capacities of actors is potentially insufficient to advance effective cooperation, but it remains necessary to understand rules-in-use and the action situations that constrain actors.

\section{Conclusions}

Remedying ineffective cooperation among Thai government organizations is critical for effective policy development and implementation, but studies on cooperation under policy processes are limited. To fill this void, the current research expanded our grasp of Thai policy processes by casting light on cooperation from an institutional perspective; this orientation was adopted given that institutions affect the decisions made by actors-an influence that, in turn, impacts policy outcomes [13]. The IAD framework was selected as the tool for carrying out the case study on collaboration among the MoEN, MoNRE, and MoI, which are involved in EFW target development and implementation under AEDP 2015. To add value to the research, we adopted the concept of cooperation intensity, which pertains to actors' interactions that involve vigorous contribution to policy work and policy outcomes. We then categorized such intensity into five levels, which are reflected in collaboration through (1) the pursuit of common goals and mutual benefits, (2) the pooling of resources, (3) the sharing of responsibilities, (4) the synchronization of activities, and (5) the monitoring of partners. This cooperation hierarchy can be used as a guide in the analysis of current and future (projected) cooperative initiatives and the advancement of enhanced collaboration.

With the five levels of cooperation intensity as a basis, we found that the causes of ineffective cooperation are differences in perceptions of MSW problems and the prioritization of solutions put forward by the individual actors; the actors' commitment to different solutions; the inconsistency among responsibilities, actions, and control over the outcomes of the actors; the failure of the actors to clarify and synchronize related and duplicate policy activities; and the unwillingness of the actors to undergo checking and monitoring. These causes, as determined from the IAD framework, stemmed from the effects of rules-in-use - especially informal information, aggregation, and scope rules—on the actors' behaviors and decisions. Changing rules is not an easy task, and altering actors' behaviors instantly is difficult to accomplish. To improve cooperation, we recommend obligating all actors to thoroughly communicate with their partners at every cooperation intensity level as good understanding among actors, particularly with regard to individual needs and limitations, is crucial to collaboration and improvements to cooperation intensity in the future. Because Thai government organizations evaluate their performance twice a year, the satisfaction of their partners with communication should be used as a performance criterion.

Similar to other studies, the present study is encumbered with certain limitations. First, our findings were obtained from an ex-post analysis characterized by a limited number of variables and constraints. Second, the proposed classification of cooperation intensity is a simplified one, when in reality, cooperation does not occur as systematically and as linearly as described in this research. The establishment of cooperation can proceed backward, in a combined fashion, or be disregarded altogether. It is hoped, however, that the lessons learned from the case study and the recommendations will benefit future research on policy development and implementation, especially in service of the next revision of AEDP 2015.

For further research, scholars can look into the effects of institutions that govern other patterns of interaction that affect effective policy development and implementation by actors. These patterns include negotiation, communication, and ignorance. Researchers can also investigate the evaluative criteria used in assessing the connections between cooperative behaviors and their outcomes.

Author Contributions: Conceptualization, H.C. and T.W.; data collection and interview, H.C.; data and result analysis, H.C. and T.W.; supervision, T.W.; writing—original draft, H.C.; writing—review and editing, H.C. and T.W.

Funding: This research received no external funding. 
Acknowledgments: The authors would like to thank the interviewees for their valuable information and generous cooperation.

Conflicts of Interest: The authors declare no conflict of interest.

\section{Acronyms}

$\begin{array}{ll}\text { AEDP } & \text { Alternative Energy Development Plan } \\ \text { EFW } & \text { Energy from waste } \\ \text { EIA } & \text { Environment Impact Assessment } \\ \text { FiTs } & \text { Feed-in-Tariffs } \\ \text { GHG } & \text { Green House Gas } \\ \text { KTOE } & \text { Kilo Tons of Oil Equivalent } \\ \text { IAD } & \text { Institutional Analysis and Development } \\ \text { LCOE } & \text { Leverized Cost of Energy } \\ \text { MoEN } & \text { Ministry of Energy } \\ \text { MoNRE } & \text { Ministry of Natural Resources and Environment } \\ \text { MoI } & \text { Ministry of Interior } \\ \text { MSW } & \text { Municipal Solid Waste } \\ \text { tCO } & \text { Ton of } \mathrm{CO}_{2} \text { equivalent } \\ \text { WMS }^{2} & \text { Waste } \mathrm{Management} \mathrm{System}\end{array}$

\section{References}

1. Pandey, B.K.; Vyas, S.; Pandey, M.; Gaur, A. Municipal solid waste to energy conversion methodology as physical, thermal, and biological methods. Curr. Sci. Perspect. 2016, 2, 39-44.

2. ONEP Statistics of Thai Imported and Exported Energy. 2016. Available online: http://www.onep.go.th/env_ data/2016/01_17/ (accessed on 20 May 2019).

3. Santhoshkumar, A.; Kumar, R.M.D.; Babu, D.; Thangarasu, V.; Anand, R. Effective utilization of high-grade energy through thermochemical conversion of different wastes. In Pollutants from Energy Sources; Springer: Singapore, Singapore, 2019; pp. 189-251.

4. Mega, V.P. The paths to decarbonisation through cities and seas. In Eco-Responsible Cities and the Global Ocean; Springer International Publishing: Cham, Switzerland, 2019; pp. 121-166. ISBN 978-3-31-993680-2.

5. Sher, F.; Pans, M.A.; Sun, C.; Snape, C.; Liu, H. Oxy-fuel combustion study of biomass fuels in a $20 \mathrm{kWth}$ fluidized bed combustor. Fuel 2018, 215, 778-786. [CrossRef]

6. Sher, F.; Pans, M.A.; Afilaka, D.T.; Sun, C.; Liu, H. Experimental investigation of woody and non-woody biomass combustion in a bubbling fluidised bed combustor focusing on gaseous emissions and temperature profiles. Energy 2017, 141, 2069-2080. [CrossRef]

7. Zhang, Y.; Fang, Y.; Jin, B.; Zhang, Y.; Zhou, C.; Sher, F. Effect of Slot Wall Jet on Combustion Process in a 660 MW Opposed Wall Fired Pulverized Coal Boiler. Int. J. Chem. React. Eng. 2019, 17, 1-13. [CrossRef]

8. Department of Alternative Energy Development and Efficiency (DEDE). Alternative Energy Development Plan: AEDP 2015; Department of Alternative Energy: Bangkok, Thailand, 2015.

9. Efficiency, D. Potential Capacity of EFW by Region. Available online: http://webkc.dede.go.th/testmax/node/ 2215 (accessed on 2 April 2019).

10. Jutidamrongphan, W. Sustainable waste management and waste to energy recovery in Thailand. In Advances in Biofuels and Bioenergy; InTech: Rijeka, Croatia, 2018.

11. Department of Alternative Energy Development and Efficiency (DEDE). Action Plan for AEDP 2015; Department of Alternative Energ: Bangkok, Thailand, 2015.

12. Ministry of Energy. Alternative Energy Development Plan (AEDP); Ministry of Energy: Bangkok, Thailand, 2008.

13. Polski, M.M.; Ostrom, E. An Institutional Framework for Policy Analysis and Design; Indiana University Press: Bloomington, Indiana, 1999.

14. Edwards, G.C., III. Implementing Public Policy; Congressional Quaterly Press: Washington, DC, USA, 1980.

15. Ariti, A.T.; van Vliet, J.; Verburg, P.H. The role of institutional actors and their interactions in the land use policy making process in Ethiopia. J. Environ. Manag. 2019, 237, 235-246. [CrossRef] [PubMed] 
16. Lin, H. Knowledge sharing and firm innovation capability: An empirical study. Int. J. Manpow. 2007, 28, 315-332. [CrossRef]

17. Ferretti, V.; Pluchinotta, I.; Tsoukiàs, A. Studying the generation of alternatives in public policy making processes. Eur. J. Oper. Res. 2019, 273, 353-363. [CrossRef]

18. Marra, A.; Mazzocchitti, M.; Sarra, A. Knowledge sharing and scientific cooperation in the design of research-based policies: The case of the circular economy. J. Clean. Prod. 2018, 194, 800-812. [CrossRef]

19. Wäsche, H. Interorganizational cooperation in sport tourism: A social network analysis. Sport Manag. Rev. 2015, 18, 542-554. [CrossRef]

20. Marwell, G.; Schmitt, D.R. Introduction: The study of cooperation. In Cooperation: An Experimental Analysis; Marwell, G., Schmitt, D.R., Eds.; Academic Press, Inc.: New York, NY, USA, 1975; pp. 1-17. ISBN 0-12-476350-2.

21. Kretschmer, T.; Vanneste, B.S. Collaboration in strategic alliances: Cooperation and coordination. In Collaborative Strategy: Critical issues for Alliances and Networks; Mesquita, L.F., Ragozzino, R., Reuer, J.J., Eds.; Edward Elgar Publishing Limited: Cheltenham, UK, 2017; pp. 53-62. ISBN 978-1-78347-958-0.

22. Pechlaner, H.; Volgger, M. How to promote cooperation in the hospitality industry. Int. J. Contemp. Hosp. Manag. 2012, 24, 925-945. [CrossRef]

23. Czernek-Marszałek, K. Cooperation evaluation with the use of network analysis. Ann. Tour. Res. 2018, 72, 126-139. [CrossRef]

24. Denise, L. Collaboration Vs C-Three (Cooperation, Coordination, and Communication). Available online: https://www.sccharterschools.org/assets/documents/collaborationvsthe3cs.pdf (accessed on 3 Feburary 2019).

25. Borgatti, S.P.; Mehra, A.; Brass, D.J.; Labianca, G. Network Analysis in the Social Sciences. Science 2009, 323, 829-895. [CrossRef] [PubMed]

26. Milner, H. International theories of cooperation among nations: Strengths and weaknesses. World Political 1992, 44, 466-496. [CrossRef]

27. Das, T.K.; Teng, B. The dynamics of alliance conditions in the alliance development process. J. Manag. Stud. 2002, 39, 725-746. [CrossRef]

28. Poppo, L.; Zenger, T. Do formal contracts and relational governance function as substitutes or complements? Strateg. Manag. J. 2002, 23, 707-725. [CrossRef]

29. Luo, Y. An integrated anti-opportunism system in international exchange. J. Int. Bus. Stud. 2007, 38, 855-877. [CrossRef]

30. Arslan, B.; Ariño, A. The process of cooperation in strategic alliances. In Collaborative Strategy: Critical Issues for Alliances and Networks; Mesquita, L., Ragozzino, R., Reuer, J., Eds.; Edward Elgar Publishing Limited: Cheltenham, UK, 2017; pp. 134-143. ISBN 978-1-78347-958-0.

31. Di Porto, E.; Parenti, A.; Paty, S.; Abidi, Z. Local government cooperation at work: A control function approach. J. Econ. Geogr. 2016, 17, 435-467. [CrossRef]

32. Williamson, O.E. Markets and hierarchies. In Strategy: Critical Perspectives on Business and Management; Faulkner, D., Ed.; Routledge: London, UK, 1975.

33. Weber, B.; Heidenreich, S. When and with whom to cooperate? Investigating effects of cooperation stage and type on innovation capabilities and success. Long Range Plan. 2018, 51, 334-350. [CrossRef]

34. Park, B.J.R.; Srivastava, M.K.; Gnyawali, D.R. Walking the tight rope of coopetition: Impact of competition and cooperation intensities and balance on firm innovation performance. Ind. Mark. Manag. 2014, 43, 210-221. [CrossRef]

35. Alimov, R. The Shanghai Cooperation Organisation: Its role and place in the development of Eurasia. J. Eurasian Stud. 2018, 9, 114-124. [CrossRef]

36. Nurdin, N.; Stockdale, R.; Scheepers, H. Coordination and cooperation in e-government: An Indonesian local e-government case. Electron. J. Inf. Syst. Dev. Ctries. 2014, 61, 1-21. [CrossRef]

37. White, W.; Lunnan, A.; Nybakk, E.; Kulisic, B. The role of governments in renewable energy: The importance of policy consistency. Biomass Bioenergy 2013, 57, 97-105. [CrossRef]

38. Rudd, M.A. An institutional framework for designing and monitoring ecosystem-based fisheries management policy experiments. Ecol. Econ. 2004, 48, 109-124. [CrossRef]

39. Li, R.; van den Brink, M.; Woltjer, J. Rules for the governance of coastal and marine ecosystem services: An evaluative framework based on the IAD framework. Land Use Policy 2016, 59, 298-309. [CrossRef]

40. Ostrom, E. Institutional Analysis and Development: Elements of the framework in historical perspective. Hist. Dev. Theor. Approaches Sociol. 2010, II, 401. 
41. Ostrom, E. Understanding Institutional Diversity; Ostrom, E., Ed.; Palgrave Macmillan UK: Princeton, NJ, USA, 2005; ISBN 9780691122076.

42. Imperial, M.T. Institutional Analysis and Ecosystem-Based Management: The Institutional Analysis and Development Framework. Environ. Manag. 1999, 24, 449-465. [CrossRef]

43. Ostrom, E.; Gardner, R.; Walker, J. Rules, games, and common-pool resources. In Rules, Games, and Common-Pool Resources; The University of Michigan Press: Ann Arbor, MI, USA, 1994.

44. Ostrom, E. Background on the Institutional Analysis and Development Framework. Policy Stud. J. 2011, 39, 7-27. [CrossRef]

45. Neergaard, M.A.; Olesen, F.; Andersen, R.S.; Sondergaard, J. Qualitative description-The poor cousin of health research? BMC Med. Res. Methodol. 2009, 9, 52. [CrossRef]

46. Loeb, S.; Dynarski, S.; Mcfarland, D.; Morris, P.; Reardon, S.; Reber, S. Descriptive Analysis in Education: A Guide for Researchers; National Center for Education Evaluation and Regional Assistance: Washinton, DC, USA, 2017.

47. Kim, H.; Sefcik, J.S.; Bradway, C. Characteristics of Qualitative Descriptive Studies: A Systematic Review. Res. Nurs. Health 2017, 40, 23-42. [CrossRef]

48. Sandelowski, M. Focus on Research Methods Whatever Happened to Qualitative Description? John Wiley \& Sons: New York, NY, USA, 2000; Volume 23.

49. Sandelowski, M. What's in a name? Qualitative description revisited. Res. Nurs. Health 2009, 33, 77-84. [CrossRef]

50. Pollution Control Department (PCD). National Solid Waste Management Master Plan (2016-2021); Pollution Control Department: Bangkok, Thailand, 2016.

51. Department of Local Administration (DLA); Pollution Control Department (PCD). Action Plan "Thailand Zero Waste" (2016-2017); Pollution Control Department: Bangkok, Thailand, 2016.

52. Department of Local Administration (DLA) Action Plan "Clean Province"; Department of Local Administration: Bangkok, Thailand, 2018.

53. Department of Alternative Energy Development and Efficiency (DEDE). Annual Report 2015; Department of Alternative Energy Development and Efficiency: Bangkok, Thailand, 2015.

54. Pollution Control Department (PCD). Annual Report 2016; Pollution Control Department: Bangkok, Thailand, 2016.

55. Waste and Hazardous Substances Management Bureau. Annual Report 2017; Waste and Hazardous Substances Management Bureau: Bangkok, Thailand, 2017.

56. Pollution Control Department (PCD). Thai Pollution Annual Report 2017; Pollution Control Department: Bangkok, Thailand, 2018.

57. Pollution Control Department (PCD). Booklet on Thailand State of Pollution 2018; Pollution Control Department: Bangkok, Thailand, 2019.

58. Schofield, N. Political economy of institutions and decisions. In Architects of Political Change; Cambridge University Press: Cambridge, UK, 1990; pp. 318-319. ISBN 978-0-52-183202-1.

59. Vassanadumrongdee, S.; Kittipongvises, S. Factors influencing source separation intention and willingness to pay for improving waste management in Bangkok, Thailand. Sustain. Environ. Res. 2018, 28, 90-99. [CrossRef]

60. Bamroong, A. Thailand's Development Strategies and Prospects for the Twenty-First Century; Economic and Social Research Institution: Tokyo, Japan, 1997.

61. Lee, H. The Role of Public Administration and Bureaucracy in Thailand. Int. Area Rev. 1999, 2, 137-152. [CrossRef]

62. Pimpa, N. Amazing Thailand: Organizational Culture in the Thai Public Sector. Int. Bus. Res. 2012, 5, 35. [CrossRef]

63. Velayutham, S.; Perera, M.H.B. The influence of emotions and culture on accountability and governance. Corp. Gov. Int. J. Bus. Soc. 2004, 4, 52-64. [CrossRef]

64. Chenboonthai, H.; Watanabe, T. Organizational and Systemic Policy Capacity of Government Organizations Involved in Energy-From-Waste (EFW) Development in Thailand. Energies 2018, 11, 2501. [CrossRef]

65. Jacobsen, H.K.; Pade, L.L.; Schröder, S.T.; Kitzing, L. Cooperation mechanisms to achieve EU renewable targets. Renew. Energy 2014, 63, 345-352. [CrossRef]

66. Pennings, J.M. Interdependence and Complementarity-The Case of a Brokerage Office. Hum. Relat. 1975, 28, 825-840. [CrossRef] 
67. Perrow, C. A framework for the comparative analysis of organizations. Am. Sociol. Rev. 1967, 32, $194-208$. [CrossRef]

68. David, N.P. Factors affecting municipal land use cooperation. Land Use Policy 2015, 42, 170-182. [CrossRef]

69. Smiley, M. Collective Responsibility. The Stanford Encyclopedia of Philosophy. Available online: https://plato.stanford.edu/archives/sum2017/entries/collective-responsibility (accessed on 2 February 2019).

70. Van De Ven, A.H.; Delbecq, A.L.; Koenig, R. Determinants of Coordination Modes within Organizations. Source Am. Sociol. Rev. 1976, 41, 322-338.

71. May, L. The Morality of Groups: Collective Responsibility, Group-Based Harm and Corporate Rights; University of Nortre Dame Press: Notre Dame, IN, USA, 1987; ISBN 978-0-26-801366-0.

72. Rahman, N.; Korn, H.J. Alliance longevity: Examining relational and operational antecedents. Long Range Plan. 2014, 47, 245-261. [CrossRef]

73. Parsons, T. The Social System; Free Press: Glencoe, IL, USA, 1951.

74. Ajzen, I. The theory of planned behavior. Organ. Behav. Hum. Decis. Process. 1991, 50, 179-211. [CrossRef]

75. Smajgl, A.; Leitch, A.; Lynam, T. Outback Institutions: An application of the Institutional Analysis and Development (IAD) framework to four case studies in Australia's outback. DKCRC Rep. 2009, 31, 14-22.

76. Van Karnenbeek, L.; Janssen-Jansen, L. Playing by the rules? Analysing incremental urban developments. Land Use Policy 2018, 72, 402-409. [CrossRef]

(C) 2019 by the authors. Licensee MDPI, Basel, Switzerland. This article is an open access article distributed under the terms and conditions of the Creative Commons Attribution (CC BY) license (http://creativecommons.org/licenses/by/4.0/). 